\title{
Preeclampsia and Keap1 (rs11085735) variants and IncRNA MEG3 methylation status: Association with IncRNA MEG3 hypermethylation
}

\section{Maryam Zangeneh}

Kermanshah University of Medical Sciences

\section{Sara Heydarian}

Kermanshah University of Medical Sciences

\section{Zahra Seifi}

Kermanshah University of Medical Sciences

\section{Maryam Kohsari}

Kermanshah University of Medical Sciences

\section{Zohreh Rahimi ( $\nabla$ rahimizus@yahoo.com)}

Kermanshah University of Medical Sciences https://orcid.org/0000-0001-7589-3307

\section{Research Article}

Keywords: Preeclampsia, Keap1 (rs11085735), IncRNA MEG3, methylation, Western Iran

Posted Date: June 29th, 2021

DOl: https://doi.org/10.21203/rs.3.rs-633508/v1

License: (c) (1) This work is licensed under a Creative Commons Attribution 4.0 International License. Read Full License 


\section{Abstract}

Background. Preeclampsia (PE) is one of the complications of pregnancy. Genetic and epigenetic mechanisms are involved in the preeclampsia pathophysiology. The aims of present study were to investigate the role of Keap1 (rs11085735) variants and the methylation status of long non-coding RNAmaternally expressed gene 3 (IncRNA MEG3) in the pathogenesis of PE in a population from Western Iran with Kurdish ethnic background.

Results. There was no significant difference in the frequency of Keap1 genotypes comparing 75 patients with $\mathrm{PE}$ and 75 women with normal pregnancy. The frequencies of hemi methylated and full methylated Inc-MEG3 were 94 and $6 \%(P=0.04)$, respectively in all patients (50 women), 86.4, and 13.6\% ( $P=0.04)$, respectively in patients with severe preeclampsia and 98 and $0 \%$ in controls (50 women). The frequency of full methylated Inc-MEG3 was $14.3 \%$ in early-onset and $2.8 \%$ in late-onset preeclampsia $(P=0.12)$. The frequency of full methylated Inc-MEG3 was higher in patients with BMI $>25 \mathrm{~kg} / \mathrm{m}^{2}$ compared to normal weight patients. The PE patients had significantly higher levels of liver biomarkers (alanine aminotransferase, aspartate aminotransferase, alkaline phosphatase, and total bilirubin) and significantly lower platelet count than healthy pregnant women.

Conclusions. Hypermethylation status of Inc-MEG3 increased in patients with PE compared to controls that could be contributed in the pathogenesis and development of preeclampsia and its severe form. However, Keap1 variants might not be involved in the pathogenesis of preeclampsia.

\section{Background}

Preeclampsia (PE) is the most challenging disorder of pregnancy hypertension [1]. The pathogenesis of $\mathrm{PE}$ is not well understood $[2,3]$. Evidence suggested several theories in this regard as trophoblast cell invasion dysfunction into the myometrium that could play the leading role in PE incidence [4-6]. Endothelial cells dysfunction by trophoblast invasion and fluctuations in blood flow causes oxidative stress in trophoblast cell. Oxidative stress, a homeostatic imbalance dysregulation between oxidants and antioxidants, occurs in the early onset PE and makes it progress [4]. As Stepan et al. indicated, pregnant women with trophoblast pathologic invasion had a lower total antioxidant capacity [7]. One of the cytoprotective pathways against oxidative stress is the Nrf2-Keap1 pathway. Oxidative stress disrupts the KEAP1-NFE2L2 complex, consequences Nrf2 translocation to the nucleus, which acts as a regulatory factor and promotes the expression of antioxidant response element-dependent genes. Kelch-like $\mathrm{ECH}-$ associated protein 1 (Keap1) is a cysteine-rich-protein and critical negative regulator of Nrf2; therefore, it acts as a sensor for oxidative and electrophile stress. In normal conditions (not under oxidative stress), keap1 directs NRF2 through ubiquitination to proteasomal degradation to preserve cellular hemostasis [8].

Recently two studies investigated the effect of the Keap1-Nrf2 pathway on the biological function of trophoblast cells (HTR8/SVneo cells) in the oxidative stress model at the cellular level. Their results 
demonstrated the expression level of Keap1 in the placenta of patients with PE was slightly lower than the normal placenta $[3,6]$. Another important factor is maternally expressed gene 3 (MEG3), a long noncoding RNA (IncRNA) member, which contributes to apoptosis, proliferation, and growth. LncRNA MEG3 is typically produced by placenta cells. It has been suggested a reduction of MEG3 in placental samples of patients with preeclampsia accounts for increased apoptosis and decreased migration that might have a role in remodeling failure of uterine spiral and PE incidence [9]. Also, Yu et al. proposed declining MEG3 via downregulation of epithelial-mesenchymal transition (EMT) by the TGF- $\beta$ pathway inhibitor, which can be involved in the occurrence of PE [5].

There are no available reports related to the role of Keap1 polymorphism and MEG3 methylation in the pathogenesis of preeclampsia. So, to find the effect of Keap1 and MEG3 in the risk of PE we aimed to investigate the frequency of Keap1 (rs11085735) variants and the Lnc-MEG3 methylation status in preeclamptic patients compared with healthy individuals in a population from Western Iran with Kurdish ethnic background.

\section{Methods}

In a case-control study, 150 participants recruited, after providing written consent under approval by the Ethics Committee of Kermanshah University of Medical Sciences. The study was under the Declaration of Helsinki II principles. All participants were selected from women referring to the obstetrics clinic of Imam Reza Hospital of Kermanshah University of Medical Sciences (Kermanshah, Iran) and consisted of 75 women with PE and 75 women with normal pregnancy as controls. A sample of 75 patients was used to evaluate the variants of Keap1, and a sample of 50 patients was used to examine the methylation status of IncMEG3. The number of healthy individuals in both analyses was equal to patient samples.

Preeclampsia was defined as systolic and diastolic blood pressure equal to or higher 140 and $90 \mathrm{mmHg}$, the presence of proteinuria confirmed by excreting more than $300 \mathrm{mg}$ protein in a 24-hours urine test or detecting $30 \mathrm{mg} / \mathrm{dl}$ or more in a randomized urine sample (1 + reaction on dipstick), the urine protein to creatinine ratio bigger than 0.3 . Severe preeclampsia was defined as having one or more of the following criteria, blood pressure equal or higher than 160/110 mmHg after twice measurement and 6 hours apart while the patient was resting on the bed. Blood pressure equal or higher than $160 / 110 \mathrm{mmHg}$ after twice measurement, which at least 6 hours apart, and the patient was resting on the bed. Proteinuria $>+3$ on 2 random urine samples collected at least $4 \mathrm{~h}$ apart, elevated serum level of creatinine and transaminase, thrombocytopenia, visual disturbances, upper abdominal pain, headache, and fetal growth restriction [10]. Early-onset preeclampsia was defined as preeclampsia before 34 weeks of gestation that was detected in 20 patients. Patients with diabetes, gestational diabetes, infection, premature rupture of the bladder, oligohydramnios, polyhydramnios, valvular heart disease, chronic hypertension, and chronic kidney disease were excluded from the study.

Six $\mathrm{ml}$ blood samples were obtained from each participant. Two $\mathrm{ml}$ of each sample were transferred to a falcon tube containing a $0.5 \mathrm{mM}$ EDTA used for DNA extraction and further genetic analysis. The 
remaining blood sample without anticoagulant was centrifuged at $300 \mathrm{~g}$ for 10 minutes. Serum separated and restored in cryotubes at $-20 \mathrm{C}$. The serum concentration of blood urea, creatinine, total and direct bilirubin, and liver enzymes (including alanine aminotransferase (ALT), aspartate aminotransferase (AST), and alkaline phosphatase (ALP)) were measured by an enzymatic colorimetric assay kit (Pars Azmon kit, Tehran, Iran) according to the manufacturer's instructions and performed by automated RA1000 (Technicon, CA).

Genomic DNA was extracted from peripheral blood leukocytes using the phenol-chloroform method [11]. The Keap1 polymorphism (rs11085735) was detected using polymerase chain reaction-restriction fragment length polymorphism (PCR-RFLP). Using designed forward primer of 5'-

CTCAGCCTCCCAAAGTCCCT-3' and the reverse primer of 5'-CTCCCACGGCTGCATCCAC-3' a fragment with 300-bp was amplified. The obtained 300-bp PCR product was digested with Hinfl restriction enzyme.

Methylation Specific PCR (MSP). For bisulfite treatment of extracted DNA, $30 \mu \mathrm{L}$ of melted $2 \%$ low melt agarose was added to about $200 \mathrm{ng}$ DNA and was incubated at $65^{\circ} \mathrm{C}$ for a few minutes. To denature DNA strands, it was incubated with $\mathrm{NaOH}$ at $80^{\circ} \mathrm{C}$ for 15 minutes and re-solidifies the agarose bead by chilling on ice. By adding $10 \mathrm{mM}$ hydroquinone and $40.5 \%$ sodium bisulfite at $50^{\circ} \mathrm{C}$ for about 4 hours treatment was done. To stop bisulfite reaction and desulfonation, the beads were washed with Tris-EDTA buffer, 0.2 $\mathrm{M} \mathrm{NaOH}, 1 \mathrm{M}$ hydrochloric acid, and pure water, respectively. The washed beads were diluted in 30 microliter deionized water, heated at $80^{\circ} \mathrm{C}$ and aliquoted for PCR reaction. The MSP-PCR method was used to determine the methylation status of the IncRNA MEG3 gene promoter. After bisulfite treatment, methylation status was detected using two pairs of specific primers, un-methylated primers (forward GAGGATGGTTAGTTATTGGGGT and reverse CCACCATAACCAACACCCTATAATCACA) and methylated primers (forward GTTAGTAATCGGGTTTGTCGGC and reverse AATCATAACTCCGAACACCCGCG). In MSPPCR one pair specific is used to detect methylated status and the other is used for identifying the unmethylated template [12].

Statistical analysis. The frequencies of Keap1 variants and the IncRNA MEG3 methylation status in preeclamptic patients and controls were investigated with the $\chi^{2}$ test. The Student t-test was used to compare the quantitative data. Quantitative data presented by mean \pm SD and qualitative data presented by frequency and percentage. The SPSS version 16.0 (SPSS Inc., Chicago, IL) was used for statistical analysis. Statistical significance level was considered at the $\mathrm{P}<0.05$.

\section{Results}

Characteristic of patients with PE and healthy controls are represented in Table 1. Compared to the healthy controls, all preeclamptic patients had significantly higher levels of liver function biomarkers (ALT, AST, ALP, and total bilirubin). Preeclamptic patients had a significantly lower level of platelet (PLT) count compared to controls. In all preeclamptic patients and also in severe PE group BMI values before $(26.3 \pm$ $6.2, \mathrm{P}=0.008$, and $25.9 \pm 7.5 \mathrm{~kg} / \mathrm{m}^{2}, \mathrm{P}=0.1$, respectively) and after pregnancy $(30.2 \pm 7.2, \mathrm{P}=0.004$, and $29.9 \pm 8.4 \mathrm{~kg} / \mathrm{m}^{2}, \mathrm{P}=0.1$, respectively) were higher than controls $\left(22.8 \pm 9.2\right.$ and $25.4 \pm 11.9 \mathrm{~kg} / \mathrm{m}^{2}$, 
respectively). Distribution of Keap1 variants and IncRNA MEG3 methylation status in both patient and control groups are demonstrated in Table 2. As indicated in Table 2, there was no significant difference in the frequency of Keap1 genotypes comparing patients with PE and control women. Although, the frequency of Keap1 CC genotype was higher in all preeclamptic patients $(93.3 \%)$ and patients with severe preeclampsia (96.4\%) compared to controls $(84 \%)$ it did not reach to a statistical significant. The unmethylated IncRNA MEG3 was not detected among patients. However, the Inc-MEG3 full methylated was not found in controls. The frequencies of hemi methylated and full methylated IncRNA MEG3 were 94 and $6 \%(P=0.04)$, respectively in all patients, 86.4, and $13.6 \%(P=0.04)$, respectively in patients with severe preeclampsia and 98 and $0 \%$ in controls (Table 2). In Table 3 the frequencies of Keap 1 genotypes and Inc-MEG3 methylation status have been compared between patients with early-onset and late-onset preeclampsia. The frequency of Keap1 genotypes was not significantly different comparing patients with early-onset with late-onset preeclampsia. The frequency of full methylated Inc-MEG3 was $14.3 \%$ in earlyonset and $2.8 \%$ in late-onset preeclampsia $(p=0.12)$. Among early-onset preeclampsia 12 out of 14 patients (85.7\%) had BMI before pregnancy $>25 \mathrm{~kg} / \mathrm{m}^{2}$ compared to 21 out of $36(58.3 \%)$ in late onset preeclampsia $\left(X^{2}=3.36, P=0.066\right)$. Also, the methylation status of Inc-MEG3 was detected according to $\mathrm{BMI}$. The full methylated Inc-MEG3 was not found among patients with BMI before pregnancy $\leq 25$ $\mathrm{kg} / \mathrm{m}^{2}$ and its frequency was $9.1 \%$ among patients with BMI before pregnancy $>25 \mathrm{~kg} / \mathrm{m}^{2}\left(\chi^{2}=1.64, \mathrm{P}=\right.$ $0.2)$. 
Table 1

Characteristics of patients and controls

\begin{tabular}{|c|c|c|c|}
\hline Variables & $\begin{array}{l}\text { All Patients } \\
n=75\end{array}$ & $\begin{array}{l}\text { Severe Preeclampsia } \\
n=28\end{array}$ & $\begin{array}{l}\text { Controls } \\
n=75\end{array}$ \\
\hline Age, year & $31.5 \pm 6.6 ; p=0.018$ & $29.6 \pm 6.9 ; p=0.8$ & $29 \pm 6.1$ \\
\hline Gestational age, week & $35.3 \pm 2.2 ; p<0.001$ & $35.2 \pm 2.1 ; p<0.001$ & $37.5 \pm 2.1$ \\
\hline $\begin{array}{l}\text { Before pregnancy } \\
\text { weight, kg }\end{array}$ & $71.2 \pm 10.7 ; p=0.09$ & $70.9 \pm 13.4 ; p=0.5$ & $68 \pm 12$ \\
\hline $\begin{array}{l}\text { After pregnancy } \\
\text { weight, } \mathrm{kg}\end{array}$ & $81.3 \pm 12.7 ; p=0.4$ & $80.3 \pm 14.4 ; p=0.9$ & $79.7 \pm 12.7$ \\
\hline $\begin{array}{l}\text { Before pregnancy BMl, } \\
\mathrm{kg} / \mathrm{m}^{2}\end{array}$ & $26.3 \pm 6.2 ; p=0.008$ & $25.9 \pm 7.5 ; p=0.1$ & $22.8 \pm 9.2$ \\
\hline $\begin{array}{l}\text { After pregnancy BMl, } \\
\mathrm{kg} / \mathrm{m}^{2}\end{array}$ & $30.2 \pm 7.2 ; p=0.004$ & $29.9 \pm 8.4 ; p=0.1$ & $25.4 \pm 11.9$ \\
\hline $\begin{array}{l}\text { Systolic blood pressure, } \\
\mathrm{mm} \mathrm{Hg}\end{array}$ & $152 \pm 16.3 ; p<0.001$ & $165 \pm 17.5 ; p<0.001$ & $113.3 \pm 7.5$ \\
\hline $\begin{array}{l}\text { Diastolic blood pressure, } \\
\mathrm{mm} \mathrm{Hg}\end{array}$ & $93.3 \pm 15.2 ; p<0.001$ & $102.6 \pm 11.9 ; p<0.001$ & $73.5 \pm 5.4$ \\
\hline Platelet count & $152.7 \pm 36.3 ; p=0.026$ & $152 \pm 33.6 ; p=0.02$ & 187.247 .7 \\
\hline Urea, mg/dL & $26.2 \pm 7.3 ; p<0.001$ & $26.8 \pm 7.4 ; p<0.001$ & $19.6 \pm 6.5$ \\
\hline Creatinine, $\mathrm{mg} / \mathrm{dL}$ & $0.7 \pm 0.2 ; p=0.3$ & $0.8 \pm 0.2 ; p=0.5$ & $1.4 \pm 3.8$ \\
\hline AST, U/L & $39.2 \pm 45.5 ; p=0.001$ & $38.3 \pm 47.3 ; p=0.1$ & $19.9 \pm 7.1$ \\
\hline ALT, U/L & $28.5 \pm 27.5 ; p<0.001$ & $28.7 \pm 25 ; p=0.05$ & $15.3 \pm 8$ \\
\hline ALP, U/L & $350.5 \pm 131 ; p=0.006$ & $352.6 \pm 132.8 ; p=0.05$ & $280.1 \pm 10.8 .1$ \\
\hline Direct bilirubin, mg/dL & $0.31 \pm 0.13 ; p=0.2$ & $0.2 \pm 0.08 ; p=0.9$ & $0.2 \pm 0.1$ \\
\hline Total bilirubin, mg/dL & $0.76 \pm 0.29 ; p=0.001$ & $0.6 \pm 0.2 ; p=0.03$ & $0.57 \pm 0.26$ \\
\hline
\end{tabular}


Table 2

Distribution of keap1 and Lnc RNA MEG3 genotypes in patients with preeclampsia, severe preeclamptic patients and controls.

\begin{tabular}{|c|c|c|c|}
\hline Parameters & All patients & Severe PE patients & Controls \\
\hline Keap 1 genotypes & $N=75$ & $N=28$ & $N=75$ \\
\hline AA & $5(6.7 \%)$ & $1(3.6 \%)$ & $7(9.3 \%)$ \\
\hline \multirow[t]{2}{*}{ AC } & $0(0.0 \%)$ & $0(0.0 \%)$ & $5(6.7 \%)$ \\
\hline & $X^{2}=2.9 ; P=0.08$ & $\chi^{2}=0.67 ; P=0.4$ & \\
\hline \multirow[t]{2}{*}{ CC } & 70 (93.3\%) & 27 (96.4\%) & $63(84.0 \%)$ \\
\hline & $X^{2}=0.5 ; P=0.4$ & $\chi^{2}=1.1 ; P=0.2$ & \\
\hline Lnc RNA MEG3 genotypes & $N=50$ & $N=22$ & $N=50$ \\
\hline UU & $0(0.0 \%)$ & $0(0.0 \%)$ & $1(2.0 \%)$ \\
\hline \multirow[t]{2}{*}{ UM } & $47(94.0 \%)$ & $19(86.4 \%)$ & $49(98.0 \%)$ \\
\hline & $\chi^{2}=0.95 ; P=0.3$ & $\chi^{2}=0.38 ; P=0.5$ & \\
\hline \multirow[t]{2}{*}{ MM } & $3(6.0 \%)$ & $3(13.6 \%)$ & $0(0.0 \%)$ \\
\hline & $\chi^{2}=4.0 ; P=0.04$ & $\chi^{2}=4.0 ; P=0.04$ & \\
\hline \multicolumn{4}{|c|}{$\begin{array}{l}\text { *Overall } \chi^{2} \text { comparing three Keap } 1 \text { genotypes between all preeclamptic patients and controls is } 5.7 ; \mathrm{F} \\
=0.05\end{array}$} \\
\hline \multicolumn{4}{|c|}{$\begin{array}{l}\text { ** Overall } \chi^{2} \text { comparing three keap1 genotypes between severe preeclamptic patients and controls is } \\
0.3 ; P=0.2\end{array}$} \\
\hline \multicolumn{4}{|c|}{$\begin{array}{l}\text { \# Overall } \chi^{2} \text { comparing three LncRNA MEG3 genotypes between all preeclamptic patients and } \\
\text { controls is } 4.0 ; P=0.1\end{array}$} \\
\hline \multicolumn{4}{|c|}{$\begin{array}{l}\text { \#\# Overall } \chi^{2} \text { comparing three LncRNA MEG3 genotypes between severe preeclamptic patients and } \\
\text { controls is } 7.4 ; P=0.02\end{array}$} \\
\hline
\end{tabular}


Table 3

Distribution of Keap1 and IncRNA MEG3 genotypes in early-onset and late-onset preeclampsia.

\section{Parameters Early-onset preeclampsia Late-onset preeclampsia}

Keap1 genotypes

$\begin{array}{lll}\text { AA } & 1(6.3 \%) & 4(6.8 \%) \\ \text { AC } & 0 & 0 \\ \text { CC } & 15(93.8 \%) & 55(93.2 \%)\end{array}$

LncRNA MEG3 genotypes

UU 0

$\begin{array}{ll}\text { UM } & 12(85.7 \%) \\ & 35(97.2 \%)\end{array}$

$\chi^{2}=0.1 ; P=0.6$

$\begin{array}{ll}\text { MM } 2(14.3 \%) & 1(2.8 \%)\end{array}$

*Overall $\chi^{2}$ comparing three keap1 genotypes between early-onset preeclamptic patients and lateonset preeclamptic patients is $0.006 ; \mathrm{P}=0.94$

${ }^{\star *}$ Overall $\chi^{2}$ comparing three IncRNA MEG3 genotypes between early-onset preeclamptic patients and late-onset preeclamptic patients is $2.4 ; \mathrm{P}=0.12$

\section{Discussion}

The present study investigated the biochemical and hematological parameters and also the frequency of Keap1 variants and IncRNA MEG3 methylation status in preeclamptic patients compared with women with normal pregnancy in a population from Western Iran. Compared with healthy pregnant women, a significant difference in liver function tests (ALT, AST, ALP, and total bilirubin) was detected in patients with PE. Patients with PE had higher serum levels of liver function tests except for direct bilirubin. During pregnancy, hormonal changes cause the dysfunction of hepatocytes, and a slight increase in ALP levels occurred in pregnancy. On the other hand, the serum concentration of ALT and AST usually remains normal. Evaluation of women with PE indicated dramatically increased serum levels of ALT, AST, ALP, and total bilirubin in these patients than normal pregnant women and these elevations might contribute to PE development. However, the direct bilirubin level did not significantly increase in patients compared to controls [13-15]. Also, elevated liver enzymes eventuate with emerging of HELLP syndrome. HELLP syndrome is a pregnancy disorder with clinical emersion hemolysis, elevated liver enzymes, and low PLT count and generally considered a type of severe PE [16], although studies demonstrated HELLP can be overlapped with early-onset preeclampsia [17]. Consistent with reports, our results showed a significantly lower PLT count in all and severe PE subjects than the healthy group. Evaluation of renal function can effectively diagnose gestational hypertension, as elevated urea and creatinine levels might be diagnostic and predictive biomarkers of PE $[18,19]$. We found a higher level of blood urea in patients than in healthy 
subjects. Previous studies have represented obesity as a risk factor for PE [20]. Our study demonstrated that mothers in the PE group before pregnancy were overweight and had BMI above $25 \mathrm{~kg} / \mathrm{m}^{2}$.

In the present study, we investigated the frequency of Keap1 variants. The Nrf2-keap1 pathway is one of the leading mechanisms against oxidative stress. Keap1 acts as an adaptor protein for Cul3-based E3 ubiquitin ligase; therefore, via Nrf2 proteasomal degradation regulates its function negatively. The expression of Nrf2 downstream target genes are regulated by genetic variations in the Keap1 or NFE2L2 gene [8]. There is no available study related to the frequency of Keap1 genotypes in preeclampsia and their influence on the risk of preeclampsia. Some studies established intronic rs 11085735 SNPs polymorphism of Keap1 correlated with several diseases. Siedlinski et al., in a prospective study, expressed that rs 11085735 in Keap1 was associated with a higher Forced Expiratory Volume in 1 second and might be associated with the risk of Chronic Obstructive Pulmonary Disease [21]. Variant rs11085735 minor allele (A) was associated with lower Keap1 and higher nuclear Nrf2 expression and reduced overall survival in breast cancer patients treated with radiotherapy and tamoxifen [22]. Testa et al. demonstrated that the rs 110857735 polymorphism of the Keap1 gene strongly predicts incident cardiovascular events in chronic kidney disease patients [23]. Studies on trophoblast cell line (HTR8 / SVneo) obtained from PE patients showed decreased Keap1 and increased Nrf2 expression in HTR8 / SVneo cells $[3,6]$. However, we could not found an association between the rs11085735 Keap1 variant and PE, even between early-onset and late-onset PE subjects. Lnc RNA is a transcript with more than 200 nucleotides that plays role in biological regulations such as DNA methylation, cell-cycle regulation, apoptosis, and angiogenesis with the incidence and the progression of numerous diseases. Recent observations illustrated the role of Inc RNA in trophoblast motility and migration. The Inc-MEG3 is one of the long non-coding RNAs that located in chromosome 14q. The Inc-MEG3 downregulation is correlated with PE through suppression of migration, invasion, and epithelial-mesenchymal transition of placental trophoblast cells [24]. Zhang et al. indicated down-regulation of MEG3 triggered apoptosis and repressed cell migration in trophoblast cells in vitro; consequently, it correlated with uterine spiral artery remodeling failure and participated in PE pathogenesis. The Inc-MEG3 provoked apoptosis of trophoblast cells via $\mathrm{NF}-\mathrm{KB}$ and $\mathrm{Bax} / \mathrm{Bcl} 2$ signaling pathways [9]; also, Yu et al. declared that the Inc-MEG3 downregulation is involved in PE through suppression of migration, invasion, and EMT of placental trophoblast cells by TGF- $\beta$ pathway inhibitors [5]. Epigenetic changes such as DNA methylation are influenced by environmental factors including life style [25].

In the current study, we found a significant difference between PE patients and also severe PE with the healthy group regarding methylation status of Inc-MEG3. Patients with PE had a higher frequency of IncMEG3 methylation than the healthy group. Also, among patients with preeclampsia, women with earlyonset PE had a higher rate of Inc-MEG3 methylation than late-onset preeclampsia. Since, hypermethylation of this gene decreases its expression and the Inc-MEG3 downregulation is involved in $P E$ pathogenesis [5] it seems hypermethylation of this gene in preeclamptic patients especially in severe preeclampsia be associated with the risk of preeclampsia and its severe form. Also, the frequency of IncMEG3 full methylated was higher among overweight patients compared to normal weight ones. Further, 
overweight patients had higher frequency among patients with early-onset preeclampsia compared to late-onset preeclampsia. So, there might be a role for obesity in the pathogenesis of severe form of preeclampsia through Inc-MEG3 methylation that needs to be elucidated.

\section{Conclusions}

We found biochemical and hematological parameters such as ALT, AST, ALP, total bilirubin, urea, and PLT count levels were significantly different comparing PE patients with the healthy group that is considered in PE diagnosis. The present study detected increased hypermethylation status of Inc-MEG3 in patients with PE compared to controls that could be associated with the risk of preeclampsia and its severe form. Also, the role of obesity in the pathogenesis of preeclampsia through gene methylation should be elucidated. However, we found no difference in the frequency of Keap1 genotypes between the preeclamptic patients and controls.

\section{Abbreviations}

\section{ALT}

Alanine aminotransferase

ALP

Alkaline phosphatase

AST

Aspartate aminotransferase

BMI

Body mass index

HELLP

Hemolysis, elevated liver enzymes, and low PLT count

Keap1

Kelch-like $\mathrm{ECH}$-associated protein 1

LncRNA

Long non coding RNA

MEG3

Maternally expressed gene 3

MSP-PCR

methylation-specific PCR

PCR-RFLP

Polymerase chain reaction-restriction fragment length polymorphism

PE

Preeclampsia

TGF

transforming growth factor 


\section{Declarations}

Ethics approval and consent to participate. Written consent was provided from participants. The study was approved by the Ethics Committee of Kermanshah University of Medical Sciences (the research project code 990654) and was under the Declaration of Helsinki II principles.

Consent for publication. Not Applicable.

Availability of data and material. The datasets used and/or analysed during the current study are available from the corresponding author on reasonable request.

Competing interests. The authors declare that they have no conflict of interest.

Funding. This work was financially supported by a grant from Vice Chancellor for Research of Kermanshah University of Medical Sciences, Kermanshah, Iran.

Authors' contributions. MZ diagnosed patients and provided samples. SH and ZS diagnosed patients and involved in doing experiments. MK wrote the first draft of the manuscript. ZR designed the study and critically revised the manuscript. All authors read and approved the final manuscript.

Acknowledgements. This work was performed in partial fulfillment of the requirements for MD degree of Dr. Sara Heydarian Dr. Zahra Seifi.

\section{References}

1. Macedo TC, Montagna E, Trevisan CM, Zaia V, de Oliveira R, Barbosa CP, et al. Prevalence of preeclampsia and eclampsia in adolescent pregnancy: A systematic review and meta-analysis of 291,247 adolescents worldwide since 1969. European Journal of Obstetrics \& Gynecology and Reproductive Biology. 2020;248:177-86.

2. Huppertz B. Placental origins of preeclampsia: challenging the current hypothesis. Hypertension. 2008;51(4):970-5.

3. Qiu D, Wu J, Li M, Wang L, Zhu X, Chen Y. Impaction of factors associated with oxidative stress on the pathogenesis of gestational hypertension and preeclampsia: A Chinese patients based study. Medicine. 2021;100(11).

4. Kweider N, Wruck C, Rath W. New insights into the pathogenesis of preeclampsia-the role of nrf2 activators and their potential therapeutic impact. Geburtshilfe und Frauenheilkunde. 2013;73(12):1236.

5. Yu L, Kuang L-Y, He F, Du L-L, Li Q-L, Sun W, et al. The role and molecular mechanism of long nocoding RNA-MEG3 in the pathogenesis of Preeclampsia. Reproductive Sciences. 2018;25(12):1619-28. 
6. Feng H, Wang L, Zhang G, Zhang Z, Guo W. Oxidative stress activated by Keap-1/Nrf2 signaling pathway in pathogenesis of preeclampsia. International journal of clinical and experimental pathology. 2020;13(3):382.

7. Stepan H, Heihoff-Klose A, Faber R. Reduced antioxidant capacity in second-trimester pregnancies with pathological uterine perfusion. Ultrasound in Obstetrics and Gynecology: The Official Journal of the International Society of Ultrasound in Obstetrics and Gynecology. 2004;23(6):579-83.

8. Dhamodharan U, Ponjayanthi B, Sireesh D, Bhakkiyalakshmi E, Ramkumar KM. Association of single-nucleotide polymorphisms of the KEAP1 gene with the risk of various human diseases and its functional impact using in silico analysis. Pharmacological research. 2018;137:205-18.

9. Zhang Y, Zou Y, Wang W, Zuo Q, Jiang Z, Sun M, et al. Down-regulated long non-coding RNA MEG3 and its effect on promoting apoptosis and suppressing migration of trophoblast cells. Journal of cellular biochemistry. 2015;116(4):542-50.

10. Rezavand N, Tabarok S, Rahimi Z, Vaisi-Raygani A, Mohammadi E, Rahimi Z. The effect of VDR gene polymorphisms and vitamin $\mathrm{D}$ level on blood pressure, risk of preeclampsia, gestational age, and body mass index. Journal of cellular biochemistry. 2019;120(4):6441-8.

11. Rahimi Z, Felehgari V, Rahimi M, Mozafari H, Yari K, Vaisi-Raygani A, Rezaei M, Malek-Khosravi $\mathrm{Sh}$, Khazaie $\mathrm{H}$. The frequency of factor $\mathrm{V}$ Leiden mutation, ACE gene polymorphism, serum ACE activity and response to ACE inhibitor and angiotensin II receptor antagonist drugs in Iranians type II diabetic patients with microalbuminuria. Mol Biol Rep. 2011;38(3):2117-23

12. Kagami M, Sekita Y, Nishimura G, Irie M, Kato F, Okada M, et al. Deletions and epimutations affecting the human 14q32. 2 imprinted region in individuals with paternal and maternal upd (14)-like phenotypes. Nature genetics. 2008;40(2):237-42.

13. Dacaj R, Izetbegovic S, Stojkanovic G, Dreshaj S. Elevated liver enzymes in cases of preeclampsia and intrauterine growth restriction. Medical Archives. 2016;70(1):44.

14. Belirteçleri PM, Riyad SAdYB. Liver Function Tests as Probable Markers of Preeclampsia-A Prospective Study Conducted in Riyadh. J Clin Anal Med 2015;6(4): 461-4

15. Cho GJ, Kim HY, Park JH, Ahn KH, Hong SC, Oh MJ, et al. Prepregnancy liver enzyme levels and risk of preeclampsia in a subsequent pregnancy: A population-based cohort study. Liver International. 2018;38(5):949-54.

16. Hassanpour S, Karami S. Evaluation of Hepatic Biomarkers in Pregnant Women with Preeclampsia. Gynecol Obstet (Sunnyvale). 2018;8(487):2161-0932.1000487. 
17. Varkonyi T, Nagy B, Füle T, Tarca A, Karaszi K, Schönléber J, et al. Microarray profiling reveals that placental transcriptomes of early-onset HELLP syndrome and preeclampsia are similar. Placenta. 2011;32:S21-S9.

18. Kuper SG, Tita AT, Youngstrom ML, Allen SE, Tang Y, Biggio JR, et al. Baseline Renal Function Tests and Adverse Outcomes in Patients With Chronic Hypertension. Obstetrics and gynecology. 2016;128(1):93.

19. Ambad RS, Dhok D. The role of serum urea, creatinine, uric acid in diagnosis of pre-eclampsia and eclampsia. Int J Med Biomed Stud. 2019;3:77-80.

20. Phipps E, Prasanna D, Brima W, Jim B. Preeclampsia: updates in pathogenesis, definitions, and guidelines. Clinical Journal of the American Society of Nephrology. 2016;11(6):1102-13.

21. Siedlinski M, Postma DS, Boer JM, van der Steege G, Schouten JP, Smit HA, et al. Level and course of FEV 1 in relation to polymorphisms in NFE2L2 and KEAP1 in the general population. Respiratory research. 2009;10(1):1-12.

22. Hartikainen JM, Tengström M, Winqvist R, Jukkola-Vuorinen A, Pylkäs K, Kosma V-M, et al. KEAP1 genetic polymorphisms associate with breast cancer risk and survival outcomes. Clinical Cancer Research. 2015;21(7):1591-601.

23. Testa A, Leonardis D, Spoto B, Sanguedolce MC, Parlongo RM, Pisano A, et al. A polymorphism in a major antioxidant gene (Kelch-like $\mathrm{ECH}$-associated protein 1) predicts incident cardiovascular events in chronic kidney disease patients: an exploratory study. Journal of hypertension. 2016;34(5):928-34.

24. Moradi M-T, Rahimi Z, Vaisi-Raygani A. New insight into the role of long non-coding RNAs in the pathogenesis of preeclampsia. Hypertension in pregnancy. 2019;38(1):41-51.

25. Gallardo-Escribano C, Buonaiuto V, Ruiz-Moreno MI, Vargas-Candela A, Vilches-Perez A, BenitezPorres $\mathrm{J}$, et al. Epigenetic approach in obesity: DNA methylation in a prepubertal population which underwent a lifestyle modification Clinical Epigenetics. 2020; 12:144 